\title{
Presence of highly repetitive DNA sequences in Tribolium flour-beetles
}

\author{
CARLOS JUAN, PATRICIA VAZQUEZ*, JOSE M. RUBIO*, EDUARD PETITPIERRE \& \\ GODFREY M. HEWITT* \\ Laboratori de Genètica, Departament de Biologia Ambiental, Universitat de les Illes Balears, Palma de Mallorca 07071. \\ Spain and *School of Biological Sciences, University of East Anglia, Norwich NR4 7TJ, U.K.
}

\begin{abstract}
Digestion of genomic DNA from seven species of Tribolium (Coleoptera) with Sau3AI, TaqI and ClaI restriction enzymes shows the presence of remarkable amounts of highly repetitive DNA sequences in these species. In Tribolium freemani the sequences are tandemly repeated with a satellite monomer of $166 \mathrm{bp}$, A-T rich (70.5 per cent), representing 31 per cent of the total genome and located in centromeric chromosome areas as demonstrated by in situ hybridization. The sequence has the potential to form secondary structures such as stems or cruciforms due to the presence of frequent inverted repeats. Tribolium castaneum, T. anaphe and T. madens show homologous sequences to T. freemani satellite DNA but T. confusum, T. audax, T. brevicornis and other tenebrionid beetles, such as Tenebrio molitor and Misolampus goudoti, do not. A phylogenetic dendrogram, based on the homology and abundance of highly repetitive sequences deduced by dot-blot hybridization, chemotaxonomic and karyological characters, is proposed for the seven studied species of Tribolium.
\end{abstract}

Keywords: Coleopera, genus Tribolium, satellite DNA, T. freemani.

\section{Introduction}

The genomes of eukaryotic organisms usually contain highly repetitive sequences that may constitute from less than 1 per cent to more than 50 per cent of the total nuclear DNA (Skinner, 1977). These sequences can be interspersed through the genome or, more often, tandemly repeated in large clusters of DNA. These highly repetitive tandem sequences have been called 'satellite DNAs' because, initially, they were recognized through their differential buoyant density compared to that of the 'main band DNA'. The chromosomal location of these sequences is, in most cases, pericentromeric and no clear functions have been demonstrated for them although some hypotheses suggest a possible role related to chromosome pairing (Wu et al., 1988).

The comparison of satellite DNAs among groups of different mammals such as primates (Musich et al., 1980; Fanning et al., 1989), rodents (Dod et al., 1989; Redi et al., 1990) and carnivores (Fanning et al., 1988)

Correspondence: Carlos Juan Laboratori de Genètica, Departament de Biologia Ambiental, Universitat de les Illes Balears, Palma de Mallorca 07071 Spain. has shown that they can differ considerably in copy number and DNA sequence. However, some groups such as cetaceans and pinnipeds (Arnason \& Widegren, 1986, 1989; Arnason et al., 1984) share satellite DNAs with a high degree of sequence conservation among species of different genera, and this is accompanied by very slow karyotypic evolution. In these latter taxa the study of highly repeated DNA sequences has become a valuable taxonomic character even at the suborder level (Arnason \& Widegren, 1986). At the intraspecific level, concerted evolution (Dover, 1982), operating through mechanisms of amplification and homogenization of the DNA sequences, has been suggested to explain the low degree of variation of the satellite DNA families observed.

The Coleoptera constitute the largest animal group with more than 350,000 described species (Lawrence, 1982). The family Tenebrionidae is very conservative in terms of karyological evolution; nearly 60 per cent of the 200 species studied have $2 n=20$ chromosomes (Juan \& Petitpierre, 1990) but some species are known to contain large blocks of heteropycnotic chromatin in meiocytes (Smith, 1952) and variable amounts of 
C-banding positive chromosomal material (Juan \& Petitpierre, 1989). Tenebrio molitor is the only beetle where the satellite DNA has been characterized (Petitpierre et al. 1988; Davis \& Wyatt, 1989; Ugarkovic et al., 1989). In this species a large portion of the genome (50-60 per cent) comprises a highly homogenous and chromosomally equilocated satellite DNA (Davis \& Wyatt, 1989; Juan et al., 1990, 1991) with a monomeric repeat unit of $142 \mathrm{bp}$.

The genus Tribolium, belonging to the same family, the Tenebrionidae, has been extensively used in genetic analysis (Sokoloff, 1972) and contains several serious pest species of stored products but little is known about it at the DNA level (Brown et al., 1990). Furthermore, the phylogenetic relationships among different Tribolium species, based on morphological, cytogenetic and allozymic data, are not in agreement with each other (Wool, 1982), and their genome sizes show no correspondence with the currently accepted taxonomic groups (Alvarez-Fuster et al., 1991).

In this paper we deal with the characterization, cloning and sequencing of the monomeric satellite DNA of Tribolium freemani, and a search for homologous sequences in other tenebrionid species related to Tribolium, like Tenebrio molitor and Misolampus goudoti, which can be taken as outgroup species. In this paper we examine the evolution of satellite DNAs and attempt to clarify the phylogeny of the group.

\section{Materials and methods}

\section{Source of specimens}

The sources of the studied specimens were as follows. Tribolium audax Halstead, T. brevicornis Lec., T. confusum Duval, T. castaneum Herbst. T. freemani Hinton and $T$. madens (Charp.) were obtained from the Tribolium Stock Center at California State University, San Bernardino (CA, U.S.A.). Tribolium anaphe Hinton was obtained from ADAS Central Science Laboratory (Slough, U.K.). Tenebrio molitor L. was obtained from a commercial dealer and Misolampus goudoti Guér. was collected from the wild in Mallorca (Spain).

\section{Isolation of genomic DNA}

Total genomic DNA was isolated from $250 \mathrm{mg}$ of pooled larvae or adults homogenized in $0.1 \mathrm{M} \mathrm{NaCl}$, $0.2 \mathrm{~m}$ sucrose, $0.01 \mathrm{~m}$ EDTA, 0.5 per cent SDS, incubated at $65^{\circ} \mathrm{C}$ for $30 \mathrm{~min}$, then placed on ice for $1 \mathrm{~h}$ after adding potassium acetate to a final concentration of $1 \mathrm{~m}$. The homogenate was then centrifuged at $5000 \mathrm{~g}$ for $10 \mathrm{~min}$. The resultant supernatant was extracted with 1 vol. of phenol saturated with $10 \mathrm{~mm}$ Tris- $\mathrm{HCl}$, 1 mM EDTA, pH 8.0 (TE), 1 vol. of phenol-chloroform-isoamyl alcohol $(50: 48: 2)$ and 1 vol. of chloroform-isoamyl alcohol $(24: 1)$ and precipitated with 2 vol. of cold ethanol. The precipitated nucleic acids were finally washed with 70 per cent ethanol, dried and dissolved in $\mathrm{TE}$ at a concentration of $0.6 \mathrm{mg} \mathrm{ml}^{-1}$.

\section{Restriction analysis}

Restriction enzymes were provided by BoehringherMannheim and Gibco BRL and the digestion conditions were as recommended by the manufacturers. Between 3 and $10 \mu \mathrm{g}$ of DNA were digested with the restriction enzyme and RNAase, and run on 1.5-2 per cent agarose gels under standard conditions (Maniatis et al., 1982).

\section{Cloning and sequencing of satellite monomers}

Whole DNA of Tribolium freemani was completely digested with Sau3AI and the band corresponding to the monomeric repeat unit was eluted from the agarose gel slice and purified according to the method described by Koenen (1988). This monomer was cloned into the BamHI site of the bacteriophage M13 and subsequently sequenced by the chain-terminating dideoxy method (Sanger et al., 1977).

\section{Labelling of probes}

DNA genomic bands from different Tribolium species corresponding to repetitive DNA were eluted from the agarose as above and radiolabelled with ${ }^{32} \mathrm{P}-\mathrm{dCTP}$ by random priming (Feinberg \& Vogelstein, 1983). The same method was used to label RF-DNA of recombinant M13 containing $T$. freemani monomeric satellite DNA.

\section{Dot-blot and Southern hybridizations}

Serial dilutions of the same amount of total DNA of each Tribolium species, Tenebrio molitor, Misolampus goudoti, plus lambda DNA as a negative control, were first blotted onto Hybond-N membranes. The blotted DNAs were then denatured with $0.5 \mathrm{~N} \mathrm{NaOH}$ and cross-linked to the membrane by exposure to ultraviolet light. Secondly, DNA digests from 1.5 per cent agarose gels were transferred to nylon membranes according to the capillary method of Southern (1975) and the DNA fixed to the membrane as above. Southern transfers and dot-blot membranes were prehybridized for $2 \mathrm{~h}$ with $2 \times \mathrm{SSC}, 5 \times$ Denhardt's solution, 0.5 per cent SDS and $100 \mu \mathrm{g} \mathrm{ml}^{-1}$ denatured 
herring sperm DNA at hybridization temperature. The radiolabelled probe was added and hybridization performed at $55^{\circ} \mathrm{C}$ for $16 \mathrm{~h}$. Following hybridization the filters were extensively washed with $2 \times \mathrm{SSC}, 0.1$ per cent SDS and $0.1 \times \mathrm{SSC}, 0.1$ per cent SDS at $37^{\circ} \mathrm{C}$. The filters were exposed to $\mathrm{X}$-ray film with intensifying screens at $-80^{\circ} \mathrm{C}$ for $1-24 \mathrm{~h}$. In a hybridization reaction the melting temperature $\left(T_{\mathrm{m}}\right)$ of the hybrid can be calculated by an empirical formula as decribed by Beltz et al. (1983). From the $\mathrm{G}+\mathrm{C}$ content of the $T$. freemani satellite of 29.5 per cent and in the hybridization conditions used we can estimate that a sequence similarity between probe and target, equal to or greater than 76 per cent, would allow the maintenance of hybrids.

\section{In situ hybridization}

Satellite DNA monomers and dimers of Tribolium freemani were non-radioactively labelled with biotin16-UTP (Manuelidis et al., 1982) by nick translation and hybridized with chromosome spreads from the same species obtained by a technique described elsewhere (Juan et al., 1990). Signal detection was performed by treatment with a streptavidin-peroxidase complex and staining with diaminobenzidine (DAB) (Ambros et al., 1986). We used preparations treated as mentioned but without a probe for in situ hybridization as a negative control.

\section{Results}

\section{Presence of highly repetitive sequences in Tribolium}

The total DNA of the seven Tribolium species used in this study was completely digested with EcoRI, HaeIII,
HinfI, Sau3AI, PstI and ClaI restriction enzymes. Three of these endonucleases induced conspicuous bands after gel electrophoresis, ethidium bromide staining and ultraviolet transillumination. Sau $3 \mathrm{AI}$ gave a band of about $170 \mathrm{bp}$ and multiples thereof in Tribolium freemani, T. anaphe and T. brevicornis DNAs, suggesting a tandem arrangement of highly repetitive DNA in these species (Fig. 1a). ClaI also induced bands of simiar sizes in T. freemani, T. anaphe and in $T$. madens, but in this last case with a less clear ladder pattern (Fig. 1b). TaqI produced clear-cut bands in all the studied species; the bands of $T$. anaphe were identical in pattern but different in relative intensity to those obtained with both Sau3AI and ClaI. In T. freemani, however, there were some smaller bands and several extra bands (Fig. 1c). This points to the existence of more than one target site for TaqI in the $T$. freemani monomeric band.

\section{Cloning and sequencing of $\mathrm{T}$. freemani monomeric satellite DNA}

We chose the $170 \mathrm{bp}$ monomeric band of $T$. freemani produced by Sau3AI for cloning and subsequent sequence analysis. Five recombinants were randomly used to sequence in both directions. The sequence is 166 bp long, with target sites for Sau3AI, ClaI and TaqI as expected from the restriction analysis. A consensus sequence was derived from five sequenced monomers and each individual sequence compared with the consensus to determine the number and type of substitutions that had occurred (Fig. 2). Twenty-five independent substitutions were observed and their characteristics are given in Tables 1 and 2 . The substitution rate in the five variants is 3 per cent, which

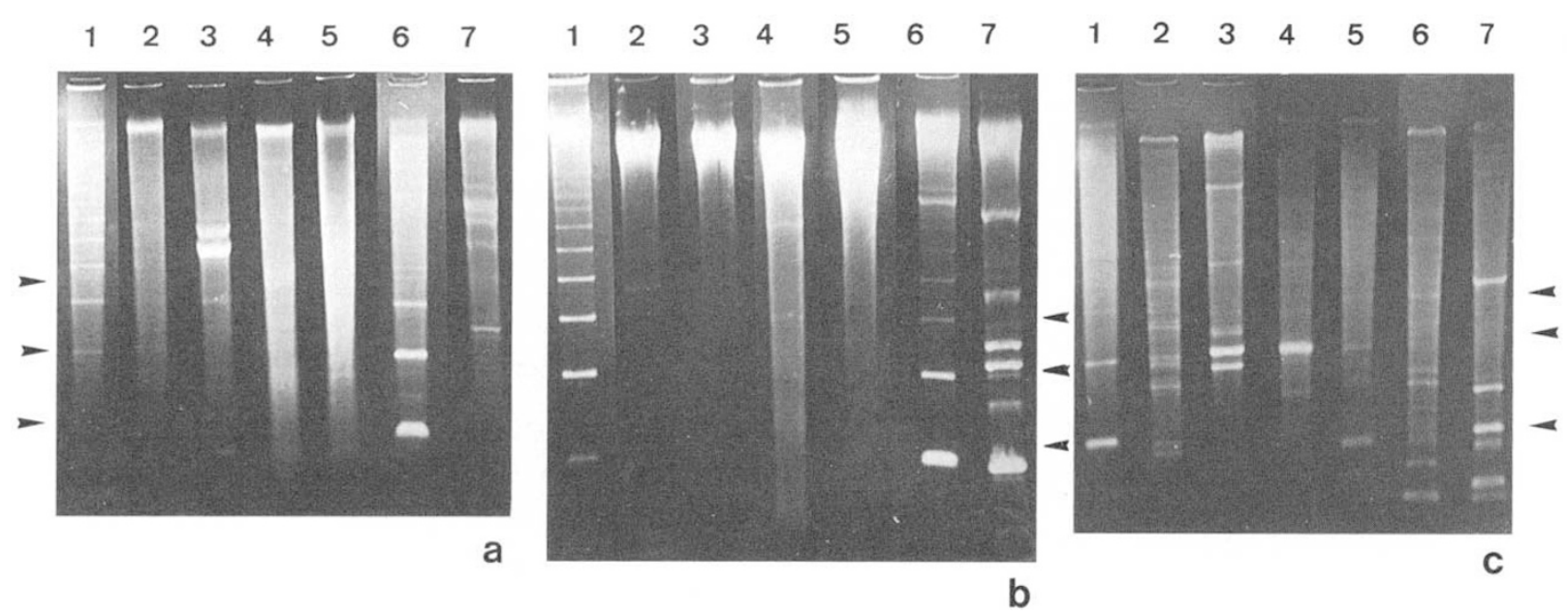

Fig. 1 Agarose gel electrophoresis of genomic DNA from different Tribolium species. Digestion with Sau3AI (a), ClaI (b) and TaqI (c). Tribolium anaphe (1); T. audax (2); T. brevicornis (3); T. castaneum (4); T. confusum (5); T. freemani (6) and T. madens (7). Monomers, dimers and trimers of 166,322 and 498 bp respectively are indicated by arrowheads. 


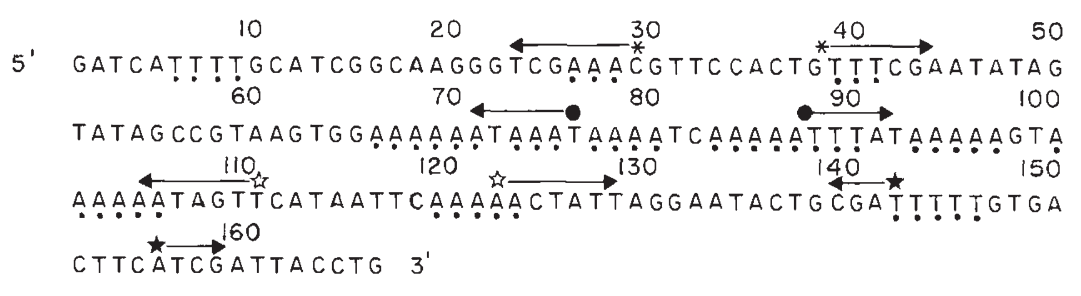

Fig.2 Nucleotide consensus sequence of Tribolium freemani satellite DNA monomeric unit. The beginning and the end of the sequence are delimited by the restriction site Sau3AI. Four regions of dyad symmetry are indicated by arrows and clusters of three or more runs of $\mathrm{A}$ or $\mathrm{T}$ nucleotides by dots. corresponds to an average of five changes per monomer, insertion/deletion events account for 3.6 shifts per monomer $(2$ per cent). The sequence is AT-rich ( 70.5 per cent) and a computer search found a remarkable richness in inverted repeats. A total of four were identified with loops of $20 \mathrm{bp}$ or less, with an homology of 100 per cent between stems (see Fig. 2) and many with lower homologies and a capacity to form cruciforms. Moreover, the satellite repeat shows 12 runs of $d(\mathrm{~A}-\mathrm{T}) n \geqslant 3$ residues (Fig. 2). No significant similarity was found after a maximum alignment with the previously described satellite DNA of Tenebrio molitor (Petitpierre et al., 1988) or with other sequences from insects in the data bank.

\section{DNA hybridization analysis}

The total digested DNA of Tribolium species did not show hybridization with a satellite DNA probe from Tenebrio molitor, as expected from the lack of sequence homology mentioned above. Sau3AI digests of Tribolium freemani, transferred to a membrane and hybridized with the cloned 170 bp Sau3AI labelled band (pTfr probe), gave almost no signal outside the ladder of repetitive bands (Fig. 3a). A total digestion of $T$. freemani DNA with TaqI and similarly probed gave an extensive ladder with multiples of $170 \mathrm{bp}$ (Fig. 3b).

On a filter containing DNA digested with TaqI of all Tribolium species, only a band of 370 bp of $T$. castaneum showed cross-hybridization with the pTfr probe (Fig. 3b). Another probe from T. anaphe, composed of monomeric and dimeric ClaI bands (pTan), was used in Southern hybridizations (Fig. 3c), this probe hybridizes with $T$. anaphe satellite DNA up to the tetramer and all the repeat ladder of $T$. freemani bands.

Dot-blot hybridization experiments were performed to deduce the gross homology and abundance of the highly repetitive sequences among the nine surveyed species of tenebrionids. Three more probes were used for this purpose: two TaqI-bands of 430 and $450 \mathrm{bp}$ from T. brevicornis (pTbr), a ClaI-band of $170 \mathrm{bp}$ from T. madens (pTma) and a TaqI-band of $370 \mathrm{bp}$ from $T$. castaneum (pTca). All five Tribolium DNA probes were used in dot-blot hybridizations with total
Table 1 Base substitutions in Tribolium freemani satellite sequence

\begin{tabular}{lllll}
\hline New base & \multicolumn{4}{c}{ Original base } \\
\hline & G & A & T & C \\
G & - & 3 & 2 & 1 \\
A & 3 & - & 2 & 2 \\
T & 2 & 3 & - & 2 \\
C & 4 & - & 1 & - \\
\hline
\end{tabular}

Table 2 Base changes in Tribolium freemani satellite sequence

\begin{tabular}{lcl}
\hline Change & Number & Ratio $(\mathrm{a}) /(\mathrm{b})$ \\
\hline (a) G, C - X & 14 & \\
(b) A, T - X & 11 & 1.27 \\
(a) Transversions & 16 & \\
(b) Transitions & 9 & 1.77 \\
\hline
\end{tabular}

$\mathrm{G}, \mathrm{C}=\mathrm{G}$ or $\mathrm{C} ; \mathrm{A}, \mathrm{T}=\mathrm{A}$ or $\mathrm{T} ; \mathrm{X}=$ any base.

denatured DNA from the seven Tribolium species plus Tenebrio molitor and Misolampus goudoti. The results are shown in Fig. 4. Only pTbr probe hybridized with all Tribolium DNAs, while none of the probes shared sufficient homology under the conditions used with the DNA from the two species of different genera. As expected from Southern analysis, the hybridization signals were slight in most cases except for the pTan probe with $T$. freemani DNA.

\section{In situ hybridization}

To detect the chromosomal localization of $T$. freemani satellite DNA we hybridized in situ the pTfr probe with chromosome spreads of the same species. Although the chromosomes of $T$. freemani are very small $(1-3 \mu \mathrm{m})$, the signal is seen to be approximately coincident with the $\mathrm{C}$-bands (Fig. $4 \mathrm{a}-\mathrm{c}$ ). The $\mathrm{C}$-bands are pericentromeric in this species, and so too is the satellite DNA. 


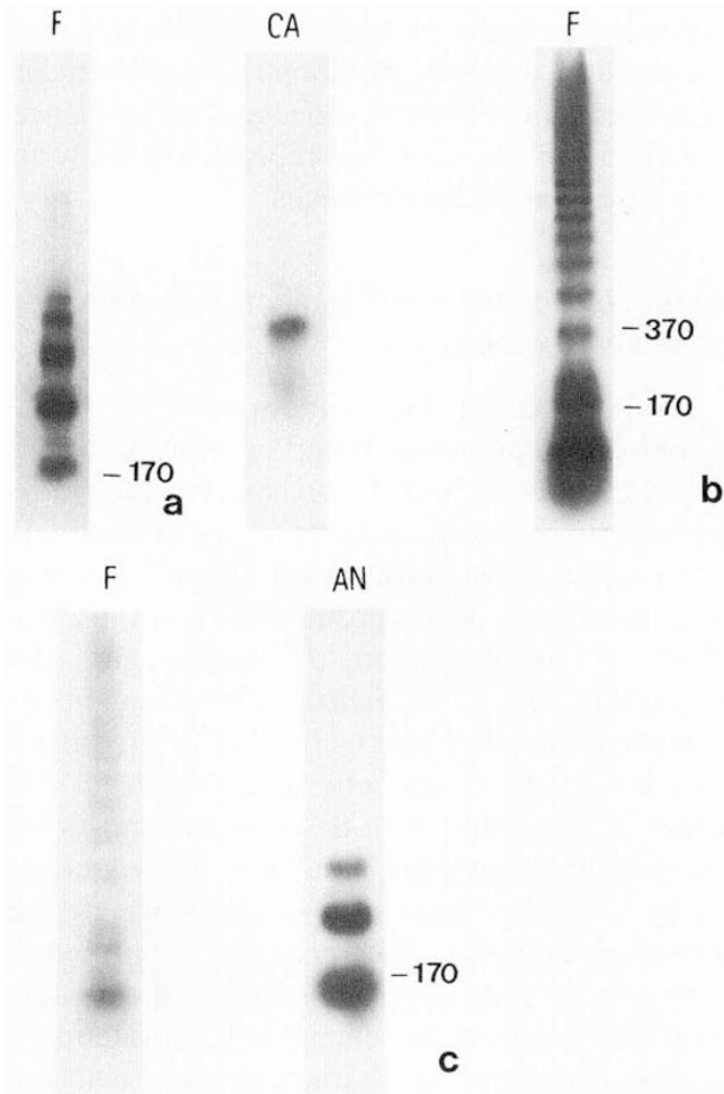

Fig. 3 (a) Tribolium freemani genomic DNA digested with Sau3AI and hybridized with pTfr probe. (b) Tribolium genomic DNAs digested with TaqI and hybridized with $\mathrm{pTfr}$ probe and (c) with pTan probe. (See text for details). AN: $T$. anaphe; CA: T. castaneum; F: T. freemani.

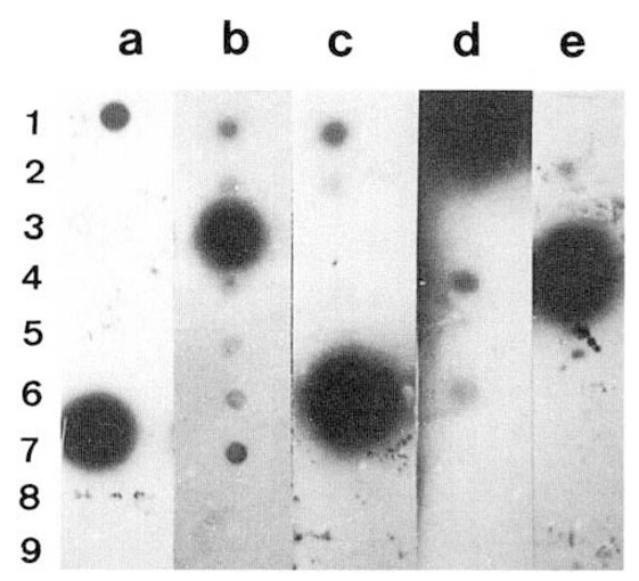

Fig. 4 Dot-blot hybridization results. Genomic DNAs $(3 \mu \mathrm{g})$ from Tribolium freemani (1); T. audax (2); T. brevicomis (3); T. madens (4); T. confusum (5); T. castaneum (6); T. anaphe (7); Tenebrio molitor (8) and Misolampus goudoti (9) were denatured and hybridized on a nylon filter with p Tan (a); pTbr (b); pTca (c); pTfr (d) and pTma (e) labelled probes.

\section{Discussion}

\section{Satellite DNAs of Tribolium}

Species of the genus Tribolium have remarkable amounts of satellite DNAs detected by digestion with Sau3AI, ClaI or TaqI restriction enzymes. In T. freemani the contribution of this satellite DNA to the total genome is estimated at 31 per cent from densitometric scanning of photographs of agarose gels (C. Juan \& E. Petitpierre unpublished data). The great abundance of these sequences is in agreement with the cytological observations of male meiocytes described by Smith (1952). The prophase I bivalents in T. castaneum and T. confusum show large blocks of heteropycnotic pericentromeric heterochromatin. Similar blocks are present in $T$. freemani chromosomes and are the sites where the satellite DNA is actually located, as can be inferred from the in situ hybridization with a $T$. freemani satellite probe. Tenebrio molitor, a member of the same subfamily within Tenebrionidae, has half of the genome composed of one $142 \mathrm{bp}$ unique sequence tandemly repeated and localized in the pericentromeric regions of all chromosomes (Petitpierre et al., 1988; Davis \& Wyatt, 1989; Juan et al., 1990). A comparison between Tenebrio molitor and Tribolium freemani satellites failed to reveal any homology between them, suggesting a high degree of divergence in the repeated sequences of the two species. Misolampus goudoti, another somewhat related species with large C-bands constituting about 58 per cent of the total chromosome length (Juan \& Petitpierre, 1989), does not show hybridization with a $T$. freemani satellite DNA probe either.

The sequence analysis of the $T$. freemani satellite monomer shows an apparently higher substitution rate and a number of insertions/deletions than the recorded in 22 different cloned monomers of Tenebrio molitor satellite sequence, which displayed only 2.5 changes per monomer ( 1.8 per cent), without insertions and deletions (Ugarkovic et al., 1989). In T. freemani, we have found an average of five changes per monomer corresponding to a substitution rate of 3 per cent Nevertheless, we cannot exclude the possibility that some monomeric variants were cloned with a higher probability than others and/or random effects caused by the relatively low number of variants sequenced.

The changes involving $\mathrm{A}$ or $\mathrm{T}$ nucleotides are less than expected if we consider the high $\mathrm{A}+\mathrm{T}$ richness of the sequence (about 70 per cent); on the other hand the transversion/transition ratio is 1.8 , similar to that found in the satellite of the primate Callimico goeldii (Cgo satellite) with equivalent $\mathrm{A}+\mathrm{T}$ content and rate of sequence divergence (Fanning et al., 1989). 
The richness in AT pairs as in the T. molitor satellite sequence is in agreement with the DA PI positive nature of the pericentromeric regions in both species (data not shown). The frequent short direct repeats, such as AAAAT or AAAAAATTAA, could presumably have originated by saltatory replication with accumulation of mutations of these or other related AT-rich motifs, as proposed by Southern (1975) for the satellite DNA of mouse.

It has been hypothesized that secondary structures in the satellite DNA sequences, such as cruciforms, can be related to a tendency of the length of the repeat unit to fit the DNA organized in the core particle of the nucleosome (Israelewski, 1983; Fowler \& Skinner, 1985). Tenebrio molitor satellite DNA has few possibilities to form cruciforms, although its length is very close (142 bp) to the DNA in the core particle (Ugarkovic et al., 1989). Recently Plohl et al. (1990) proposed a sequence-induced DNA curvature in $T$. molitor satellite resulting in a left-handed superhelix. This would be related to DNA condensation and constitutive heterochromatin folding in this species. We do not have direct evidence of curvature in the Tribolium freemani satellite DNA but the sequence is rich in $(\mathrm{A}-\mathrm{T}) n \geqslant 3$ residues. Martínez-Balbás et al. (1989) have shown that in mouse, rat and alfa-monkey satellites, the presence of such $(\mathrm{A}-\mathrm{T}) n \geqslant 3$ residues is probably responsible for the observed DNA curvature. Moreover, there is the possibility of forming four perfect loops in the $T$. freemani satellite $166 \mathrm{bp}$ sequence, which is rather longer than the nucleosomal core particle sequence; the mentioned secondary structures could be localized reducing the length to about $140 \mathrm{bp}$.

Southern blot analysis using a $T$. freemani satellite probe shows that all these repetitive sequences are arranged in tandem clusters in the $T$. freemani genome because no hybridization is present outside the ladder of repetitive bands. Moreover, frequent mutations in the TaqI target sites give rise to multiple bands up to the 15 -mer $(\sim 2500 \mathrm{bp})$, demonstrating a high degree of tandem repetition in the satellite DNA of this species.

The hybridization between sequences of repetitive DNA of different Tribolium species was very dependent on the stringency conditions used and on the homology and relative abundance of such sequences in the genome. This is probably the reason why no reciprocal hybridization was observed between probes and specific DNA bands in some cases, such as in $T$. freemani and $T$. anaphe satellites. In fact, the relatively low $\mathrm{G}+\mathrm{C}$ content of these satellites makes it necessary to use very relaxed hybridization conditions allowing the maintenance of the hybrid between the probe and the target DNA.
The different patterns of bands obtained with the various restriction enzymes demonstrates differences in the repeat sequences between species. Full sequence analysis of clones of these various repeats will allow an accurate comparison of these changes.

\section{Phylogenetic relationships of Tribolium based on highly repetitive sequences}

Hinton (1948) classified the extant species of Tribolium into five different groups based on morphological characters. Considering our seven species of Tribolium, they can be grouped under Hinton's criterion as follows: confusum species-group with $T$. confusum and $T$. anaphe, castaneum species group with $T$. castaneum, $T$. madens, $T$. freemani and $T$. audax, and the brevicornis group with $T$. brevicornis. The latter is considered the most primitive and well differentiated from the others. Based on cytogenetic data, Smith (1952) claimed that $T$. confusum with $2 n=18$ chromosomes was derived from an ancestor similar to $T$. castaneum $(2 n=20)$ by a translocation of one autosome to the X-chromosome; later Samollow et al. (1983) provided genetic support for this hypothesis. In another study, Howard (1987) analysed the chemical components of the defensive secretions as characters for a cladistic analysis of Tribolium. Under these criteria he suggests that brevicornis and castaneum are sister species-groups without synapomorphies in common with the

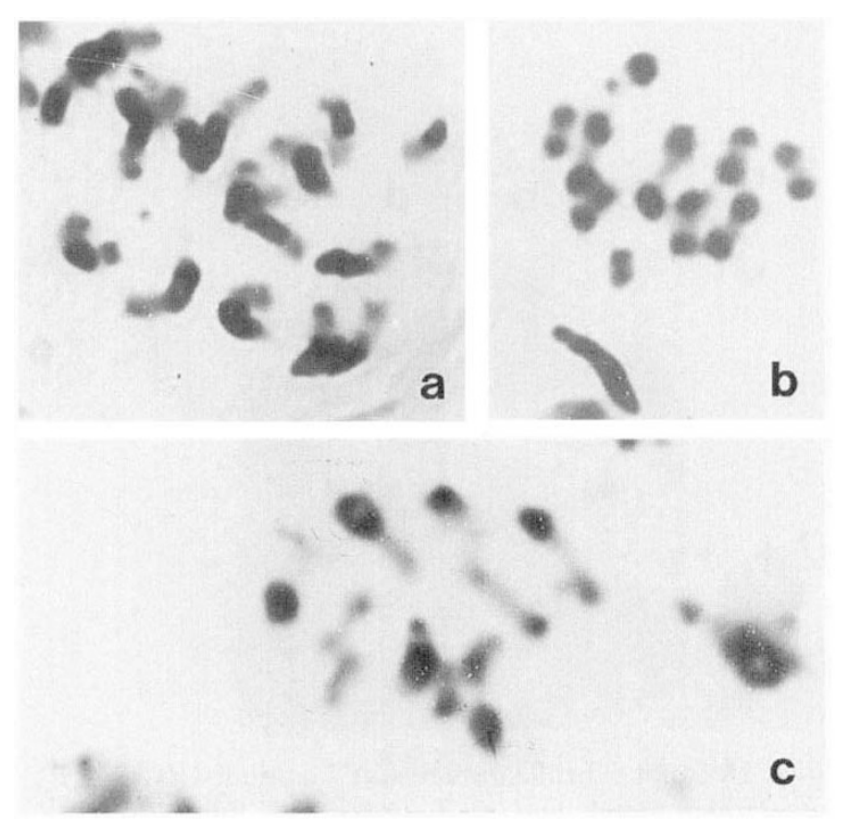

Fig. 5 C-banded spermatogonial metaphase (a) and metaphase I $(\mathbf{b})$ of Tribolium freemani. In situ hybridization of Tribolium freemani metaphase I chromosomes with a satellite DNA probe from the same species $(\mathrm{c}) . \times 2500$. 


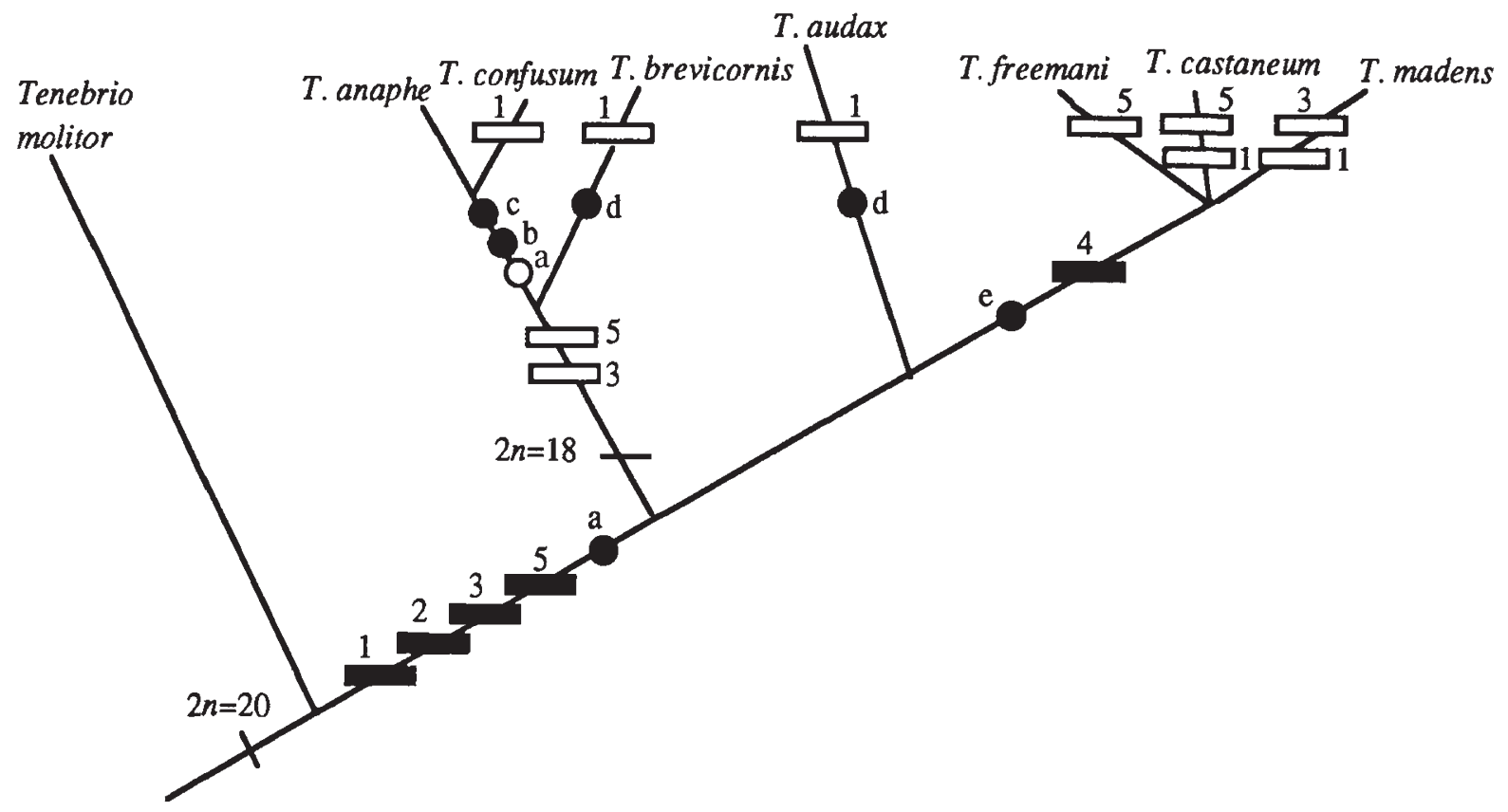

Fig. 6 Phylogeny of seven species of the genus Tribolium based on DNA hybridization data ( $\square$ ) gain, () loss. Chemotaxonomic characters given by Howard $(1987)(\bullet)$ gain, (O) loss and diploid chromosome numbers (Shimeld, 1989). Tenebrio molitor is an outgroup species.

confusum species-group and that $T$. brevicornis and $T$. audax are members of the same species-group.

The data herein, derived from the dot-blot hybridization patterns of DNA, are a simplified measure of the cross-hybridization among the different satellites. A phylogenetic analysis using PAUP (Phylogenetic Analysis Using Parsimony), based only on the hybridization data, showed a low level of evolutionary information, but if we consider the chemical compounds of defensive secretions (Howard, 1987), karyological data (Shimeld, 1989), plus the DNA hybridization data as three independent character sets, a cladrogram can be produced (Fig. 6). The castaneum species-group is well supported by the acquisition of two synapomorphies in T. castaneum, T. freemani and T. madens. On the other hand, the confusum species-group is defined by the gain of two chemical characters and the loss of two DNA characters. The brevicornis species-group, in contrast to Howard's proposed phylogeny, would be a sister of the confusum group by the shared loss of two DNA characters and the acquisition of a karyotype of $2 n=18$ derived from the ancestral $2 n=20$ (assuming reversion from $2 n=18$ to $2 n=20$ as highly unlikely). T. audax would be paraphyletic with respect to the other species-groups.

\section{Acknowledgements}

We are very grateful to $\mathrm{Dr} \mathrm{E}$. Desmarais for his valuable help on DNA cloning and sequencing and to
Dr J. Gosálvez who critically read the manuscript. The discussions with Drs C. R. Altaba and M. Palmer and suggestions from an anonymous referee substantially improved the paper. This research has been supported by projects DGICYT numbers PB87/0584 and PB90/ 0357 (Spain) and Acciones integradas Hispano Británicas' number $8 \mathrm{~A}$. The satellite DNA sequence has been deposited in EMBL under accession number X58539.

\section{References}

ALVAREZ-FusTer, A., JUAN, C. AND PETITPIERRE, E. 1991. Genome size in Tribolium flour-beetles: inter- and intraspecific variation. Genet. Res., 58, 1-5.

AMBRos, P. F., MATZKE, M. A. AND MATZKE, A. J. M. 1986. Detection of a $17 \mathrm{~kb}$ unique sequence (T-DNA) in plant chromosomes. Chromosoma, 94, 11-18.

ARNASON, U., HÖGLUND, M. AND WIDEGREN, B. 1984. Conservation of a highly repetitive DNA in cetaceans. Chromosoma, 89, 238-242.

ARNASON, U. AND WIDEGREN, B. 1986. Pinniped phylogeny enlighted by molecular hybridizations using highly repetitive DNA. Mol. Biol. Evol., 3, 356-365.

ARNASON, U. AND WIDEGREEN, B. 1989. Composition and chromosomal localization of cetacean highly repetitive DNA with special reference to the blue whale, Balenoptera musculus. Chromosoma, 98, 323-329.

BELTZ, G. A., JACOBS, K. A., EICKBUSH, T. H., CHERBAS, P. T. AND KAFATOS, F. C. 1983. Isolation of multigene families and determination of homologies by filter hybridization methods. Meth. Enzymol, 100, 266-285. 
BROWN, S. J., HENRY, J. K., BLACK IV, W. C. AND DENELL, R. E. 1990. Molecular genetic manipulation of the red flour beetle: genome organization and cloning of a ribosomal protein gene. Insect Biochem., 20, 185-193.

DAVIS, C. A. AND WYATT, G. R. 1989. Distribution and sequence homogeneity of an abundant satellite in the beetle, Tenebrio molitor. Nucl. Acids Res., 17, 5579-5586.

DOD, B., MOTTEZ, E., DESMARAIS, E., BONHOMME, F. AND ROIZES, G. 1989. Concerted evolution of light satellite DNA in genus Mus implies amplification and homogenization of large blocks of repeats. Mol. Biol. Evol., 6, 478-491.

DOVER, G. A. 1982. Molecular drive: a cohesive mode of species evolution. Nature, 285, 111-117.

FANNING, T. G., MODI, W. S., WAYNE, R. K. AND O'BRIEN, S. J. 1988. Evolution of heterochromatin-associated satellite DNA loci in felids and canids (Carnivora). Cytogenet. Cell Genet., 48, 214-219.

FANNing, T. G., SEUANEZ, H. N. AND FORMAN, L. 1989. Satellite DNA sequences in the neotropical marmoset Callimico goeldii (Primates, Platyrrhini). Chromosoma, 98, 396-401.

FEINBERG, A. P. AND VOGELSTEIN, B. 1983. A technique for radiolabelling DNA restriction endonuclease fragments to high specific activity. Anal. Biochem., 132, 6-13.

FOWLER, R. F. AND SKINNER, D. M. 1985. Cryptic satellites rich in inverted repeats comprise $30 \%$ of the genome of a hermit crab. J. Biol. Chem., 260, 1296-1303.

HINTON, H. E. 1948. A synopsis of the genus Tribolium MacLey with some remarks on the evolution of its species groups. Bull. Entomol. Res., 39, 13-55.

HOWARD, R. W. 1987. Chemosystematic studies of the Triboliini (Coleoptera: Tenebrionidae): phylogenetic inferences from the defensive chemicals of eight Tribolium spp., Palorus ratzeburgi (Wissmann), and Latheticus oryzae Warterhouse. Ann. Entomol. Soc. Am., 80, 398-405.

ISRAELEWSKI, N. 1983. Structure and function of an AT-rich, interspersed repetitive sequence from Chironomus thummi: solenoidal DNA, 142 bp palindrome-frame and homologies with the sequence for site specific recombination of bacterial transposons. Nucl. Acid Res., 11, 6985-6996.

JUAN, C., Gosalvez, J. AND PETITPIERRE, E. 1990. Improving beetle karyotype analysis: restriction endonuclease banding of Tenebrio molitor fixed chromosomes. Heredity, 65 , 157-162.

JUAN, C., GOSALVEZ, J., MEZZANOTTE, R. AND PETITPIERRE, E. 1991. Cytological and biochemical characterization of the in situ endonuclease digestion of fixed Tenebrio molitor chromosomes. Chromosoma, 100, 432-438.

JUAN, C. AND PETITPIERRE, E. 1989. C-banding and DNA content in seven species of Tenebrionidae (Coleoptera). Genome, 32, 834-839.

JUAN, C. AND PETITPIERRE, E. 1990. Karyological differences among Tenebrionidae (Coleoptera). Genetica, 80, 101-108.

KOENEN, M. 1989. Recovery of DNA fragments from agarose gels using liquid nitrogen. Trends Genet., 5, 137.
Lawrence, J. F. 1982. Coleoptera. In: Parker J. A. (ed.) Synopsis and Classification of Living Organisms. McGraw-Hill, New York.

MANIATIS, T., FRITSCH, E. F. AND SAMBROOK, J. 1982. Molecular Cloning. A Laboratory Manual. Cold Spring Harbor Laboratory, New York.

MANUELIDIS, L., LANGER-SAFER, P. R. AND WARD, D. C. 1982. High resolution mapping of satellite DNA using biotin-labeled DNA probes. J. Cell. Biol., 95, 619-625.

MARTINEZ-BALBAS, A., RODRIGUEZ-CAMPOS, A., GARCIA-RAMIREZ, M., SAINZ, J., CARRERA, J., AYMAMI, J. AND AZORIN, F. 1989. Satellite DNAs contain sequences that induce curvature. Biochemistry, 29, 2342-2348.

MUSICH, P. R., BROWN, F. L. AND MAIO, J. J. 1980. Highly repetitive component alpha and related alphoid DNAs in man and monkeys. Chromosoma, 80, 331-348.

PETITPIERRE, E., GATEWOOD, J., AND SCHMID, c. w. 1988. Satellite DNA from the mealworm beetle Tenebrio molitor. Experientia, 44, 498-499.

PLOHL, M., BORSTNIK, B., UGARKOVIC, D. AND GAMULIN, v. 1990. Sequence-induced curvature of Tenebrio molitor satellite DNA. Biochemie, 72, 665-670.

REDI, C. A., GARAGNA, S., DELla VALLE, G., BotTIRoli, G., DELl'orto, P., VIALE, G., PEVARELI, F. A., RAIMONDI, E. AND FOREJT, J. 1990. Differences in the organization and chromosomal allocation of satellite DNA between the European long tailed house mice Mus domesticus and Mus musculus. Chromosoma, 99, 11-17.

SAMALLOW, P. B., DAWSON, P. S. AND RUSSEL, A. R. 1983. X-linked and autosomal inheritance patterns of homologous genes in two species of Tribolium. Biochem. Genet., 21, 167-176.

SANGER, F., NICKLEN, S. AND COULSON, A. R. 1977. DNA sequencing with chain terminating inhibitors. Proc. Natl. Acad. Sci., U.S.A., 74, 5463-5467.

SHIMELD, L. 1989. A cytogenetic examination of eight species of Tribolium. Tribolium Inf. Bull., 29, 102-107.

SKINNER, D. M. 1977. Satellite DNAs. Bioscience, 27, 790-796.

SMITH, S. G. 1952. The evolution of heterochromatin in the genus Tribolium (Tenebrionidae: Coleoptera). Chromosoma, 4, 585-610.

soKoloff, A. 1972. The Biology of Tribolium, With Special Emphasis on Genetic Aspects, Vol I. Oxford University Press, Oxford.

SOUTHERN, E. M. 1975. Long periodicities in mouse satellite DNA. J. Mol. Biol., 94, 51-70.

UGARKovic, D., PLOHL, M. AND GAmulin, v. 1989. Sequence variability of satellite DNA from the mealworm Tenebrio molitor. Gene, 83, 181-183.

wool, D. 1982. Critical examination of postulated cladistic relationships among species of flour beetles (Tribolium, Tenebrionidae, Coleoptera). Biochem. Genet., 20 , 333-349.

WU, C. I., LYTTLE, T. W., WU, M. L. AND LIN, G. F. 1988. Association between a satellite DNA sequence and the responder of segregation distorter in D. melanogaster. Cell, 54, 179-189. 